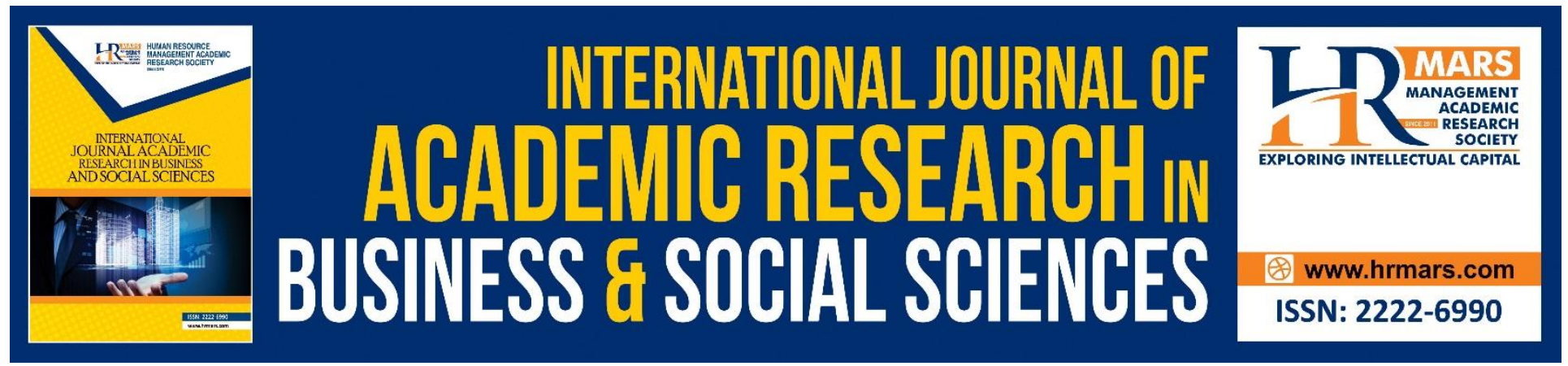

\title{
A Conceptual Framework of Sexual Harassments News Exposure's Relationship with Knowledge, Attitude, and Behavior in Pakistani and Malaysian Literature
}

Hilal Fatima, Akmar Hayati Ahmad Ghazali, Moniza Waheed, Tham Jen Sern

To Link this Article: http://dx.doi.org/10.6007/IJARBSS/v11-i15/10634

DOI:10.6007/IJARBSS/v11-i15/10634

Received: 12 May 2021, Revised: 15 June 2021, Accepted: 01 July 2021

Published Online: 26 July 2021

In-Text Citation: (Fatima et al., 2021)

To Cite this Article: Fatima, H., Ghazali, A. H. A., Waheed, M., \& Sern, T. J. (2021). A Conceptual Framework of Sexual Harassments News Exposure's Relationship with Knowledge, Attitude, and Behavior in Pakistani and Malaysian Literature. International Journal of Academic Research in Business and Social Sciences, 11(15), 4360.

\section{Copyright: (C) 2021 The Author(s)}

Published by Human Resource Management Academic Research Society (www.hrmars.com)

This article is published under the Creative Commons Attribution (CC BY 4.0) license. Anyone may reproduce, distribute, translate and create derivative works of this article (for both commercial and non-commercial purposes), subject to full attribution to the original publication and authors. The full terms of this license may be seen

at: http://creativecommons.org/licences/by/4.0/legalcode

Special Issue: Empowering Youth and Community Wellbeing for Sustainable Development, 2021, Pg. 43 - 60 http://hrmars.com/index.php/pages/detail/IJARBSS JOURNAL HOMEPAGE

Full Terms \& Conditions of access and use can be found at http://hrmars.com/index.php/pages/detail/publication-ethics 


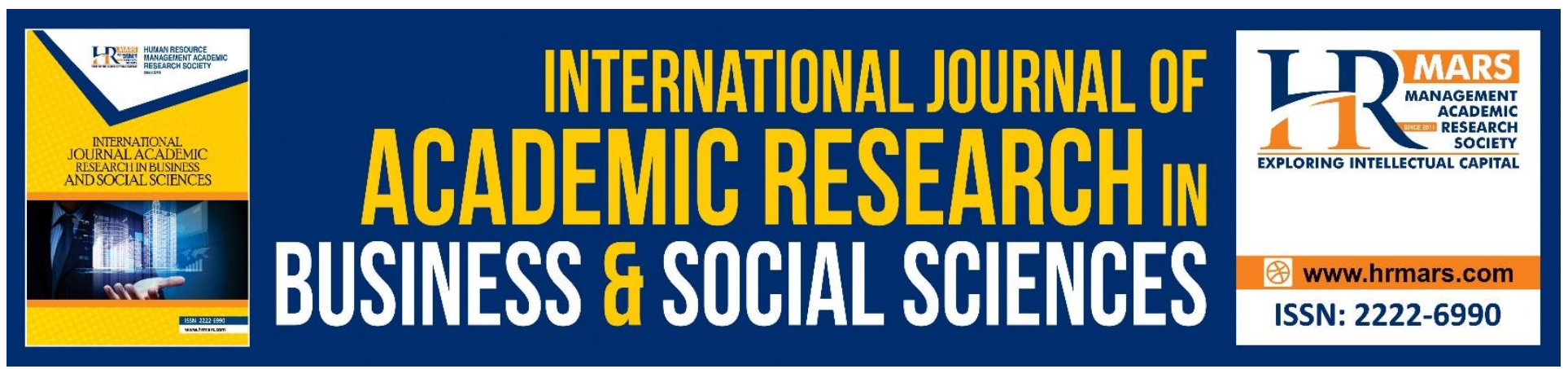

\title{
A Conceptual Framework of Sexual Harassments News Exposure's Relationship with Knowledge, Attitude, and Behavior in Pakistani and Malaysian Literature
}

\section{Hilal Fatima¹, Akmar Hayati Ahmad Ghazali ${ }^{1,2}$, Moniza Waheed¹, Tham Jen Sern ${ }^{1}$}

${ }^{1}$ Faculty of Modern Languages and Communication, Universiti Putra Malaysia, 43400, UPM Serdang, Selangor, Malaysia, ${ }^{2}$ Laboratory of Cyber Generation, Institute for Social Science Studies, Universiti

Putra Malaysia, 43400, UPM Serdang, Selangor, Malaysia

Email: akmar@upm.edu.my

\begin{abstract}
The purpose of this paper is to demonstrate the framework to researchers doing research on sexual harassments by forms of media. A conceptual approach, drawing on theoretical framework of cultivation theory, is applied. However, this paper draws a comprehensive review of previous researches that were conducted in the area of news media cultivation. This paper refers to the specific findings of the Pakistani and Malaysian literature to illustrate the research patterns with respect to identifying the relationships between sexual harassments news exposure, knowledge, intolerant attitude, and propensity to act. The paper argues on the literature results and suggestions and highlights a research gap while adding the 'sexual harassments knowledge', as an additional variable in the conceptual model. This paper provides potential reviews to conduct future studies in the perspective of media cultivation. News media needs to practice positive and informative content in sexual harassments news coverage that can provides high news exposure that enhances the knowledge, which can reform intolerant attitude with correct behavior. A framework that integrates a theoretical contribution in expanding the uses of cultivation theory in spreading awareness about sexual harassment. The findings of this study provide direction for practice and for future research on the cultivation of sexual harassments content, exposure, and relationships with other variables. The paper intends to encourage researchers to support a theoretical approach and to help practitioners better understand the reasons of tolerant attitude with wrong behavioral intentions while dealing a silent crime.
\end{abstract}

Keywords: Sexual Harassments News Exposure, Knowledge, Intolerant Attitude, Propensity to Act against Sexual Harassment 


\section{Introduction}

Awareness is the most powerful weapon for fighting against sexual harassments, and media is the best source agent to spread information and awareness. Media also plays a substantial role in the socio-economic development of society (Nautiyal and Dabral, 2012). The media has different forms like electronic, print, online that helps people to communicate at the global level. In this scenario, the people who are not able to get direct information about what is going in the world or across the boundaries, they become dependent on media (Philo, 2008).

Media has the history to develop general belief, the formation of attitude and behavior. It plays a signifying role to develop public opinion, thoughts (Alivi, et al., 2018). The media has approved its effectiveness to cultivate the mindset on a specific agenda or issue. However, in this modern age, media has their moral duty to play a role in the national development as well as on social problems, by giving solutions (Asif, 2010).

Media also has a history in playing an essential part to develop general beliefs, the formation of attitude, public opinion, thoughts, and behavior (Alivi, et al., 2018). Asif (2010) has supported this argument and discussed that media can cultivate a public mindset of a specific agenda or issue. However, in the modern age, media works for social development by giving solutions to social problems at the national level.

\section{Media Coverage}

Happer and Philo (2013) stated that media coverage of social issues could influence the development of human culture. The components and factors of media coverage can affect the process of emergence, event, or news selection. Shoemaker and Reese (1996) had highlighted the various factors that affect media coverage. The factors that influence media coverage are personal attitudes and orientations of reporters, media routines, other media organizations, and ideological factors. These factors affect the frames utilized by journalists.

The media may not reflect reality since it screens and reforms the facts. In addition, the media can highlight certain issues, which drive the general population to perceive them as more critical than others. The population can be assumed and persuaded by the content used in news coverage (Gewijzigd, 2003).

The above studies has shown that media can bring change in thoughts of general people by certain policies. In the case of sexual harassments, a big social problem, media can set particular agendas to improve sexual harassments policies and its affection and dispersion through news media (newspaper), programs, dramas, and shows through electronic media. Media can discuss causes and factors behind sexual harassments offenses that can help in the development of the public's typical mindset towards sexual harassments (Winburn and Niemeyer, 2014).

News media texts are a fruitful resource for analyzing and understand the stereotypical content about sexual harassments (Charlesworth and McDonald, 2012). The research reveals that the media most frequently reports "classic" sexual harassments and emphasizes scandalous allegations and overtly sexualized conduct (Charlesworth and McDonald, 2012). 
INTERNATIONAL JOURNAL OF ACADEMIC RESEARCH IN BUSINESS AND SOCIAL SCIENCES

Vol. 11, No. 15, Empowering Youth and Community Wellbeing for Sustainable Development, 2021, E-ISSN: 2222-6990 @ 2020 HRMARS

The 'classic', 'scandalous' and stereotypical content affects the mind of common people. The media exposure of specific agendas can cultivate attitudes and behavior against sexual harassments.

The adaptation of anti-harassing policies from the policy diffusion and innovation perspective with an emphasis on the role of print media coverage has likewise been investigated by Winburn et al., (2014). Their findings showed the importance of national media coverage efforts for policy acceptance. This study focused on system development, implementation, and dispersion as well as item visibility and attention in media coverage.

Although media has approved its effectiveness to cultivate mindset on specific agenda or issue (Alivi, et al., 2018) so that it should take a part in the coverage of sexual harassments knowledge and information to cultivate the public's views and actions against sexual harassments.

In literature, news media can influence the social-cultural norms that is why the current study is the comparison of two Asian countries literature; Malaysia and Pakistan. The literature has indicated that both countries have sexual harassments as a social problem and both countries constitute the law of sexual harassments.

Unfortunately, Pakistani media presents gender bias images, depicts sensational news, which affected negatively on the development of society (Asif, 2010). The study of Ahmed (2014), revealed that media is not sensitive about sexual harassments and gave very little space for such women violence issues e.g. sexual harassments.

In Malaysian literature, the two studies done by Alagappar and Marican (2014) shows that Malaysian newspapers are not giving proper coverage to sexual harassments legislation. Sexual harassments issue had not been considered an issue or problem for the society, which indicated no specific agenda for the awareness about this criminal offense and its prevention.

\section{Media Exposure/ Sexual Harassment News Exposure}

In this decade, studies have been done to measure sexual harassments media exposure and its relation with other variables. It indicates the important role of sexual harassments media exposure for the prevention of this criminal offense in society.

In 2000, Lonsway and Kothari had explored high sexual harassments media exposure on campus. A study done by Apaak and Sarpong (2015) had also found high sexual harassments media exposure in university students. In addition, Gurung, et al (2016) had also supported sexual harassments media exposure study and explored high exposure among students.

The above studies had shown the same pattern of higher sexual harassments media exposure among students. It indicated that students had frequently read the sexual harassments information that enhanced their understanding.

In this decade, not only the sexual harassments law formation and researches going high but also the absorption of sexual harassments information is raising. Based on the above discussion, studies of 
different countries showed high sexual harassments exposure among students that indicated an interest in sexual harassments content.

However, only one study by Sabri (2017) does not support the relation of media exposure with the perception of crime, including sexual harassments but the respondents of this study were not students in Jeddah, Saudi Arabia. There is no statistical significance between the level of newspaper exposure and the formation of their views and concepts about the crime.

In Pakistan, there is only one study done by Haider and Mashud (2014), found high media exposure to sexual criminal content that gave a bad impact and causes sexual violence. Sexual harassment is a small part of the study that is not enough for future researchers. In this situation, there is a need to fill this knowledge gap of sexual harassments news exposure and its relation with other variables.

The reason for the bad impact might be sensational and negative content of sexual harassments coverage as highlighted by Ahmed (2014). Asif (2010) had found 26 reported cases in the duration of two months and Ahmed (2014) had found $59 \%$ of sexual harassments news, which highlighted the exposure among people with negative content of sexual harassments attributes. However, these studies focused on the violence and only discussed the frequency of sexual harassments news reported in newspapers.

In addition, the same knowledge gap has been found in Malaysian literature. There is a need to study especially sexual harassments news exposure and its relation with knowledge, intolerant attitude, and behavior. The content analysis studies done by Alagappar and Marican (2013) explored the one news article of sexual harassments in a month which suggested that might be Malaysian did not have sexual harassments media exposure.

The Pakistani and Malaysian literature showed no specific study to measure sexual harassments news exposure and the content analysis studies are not enough to define the agendas behind the sexual harassments news coverage. Thorton and Wahl (1996) had given the statement, that newspaper articles about crime gave an impact on public opinion, even though the exposure of newspapers affects the public attitude. According to the author's statement; if a person has sexual harassments news exposure then negative and violent content can affect a person's attitude badly and positive content can help in the prevention.

\section{Studies on the Relation of Media Exposure/ Sexual Harassments News Exposure and Sexual Harassments Knowledge}

Wakefield, et al (2010) had explored that people who read newspapers might have more knowledge and they want to talk more and argue on issues with others and can spread awareness because news media convey the more details on specific story or incident (Happer and Philo, 2013). A person can absorb the information from the media that is why it influences to change any one's opinion. Aransay, et al (2015) supports that exposure to newspapers has a relationship with knowledge.

Exposure to media contributes to extend the awareness and knowledge and tells about all facts (Asp, et al., 2014). In the case of sexual harassments, Apaak and Sarpong, (2015) investigated the issue of sexual harassments and its related knowledge in university students and explored that mass media 
is the leading source of information on sexual harassments that is why mostly female athlete students have higher sexual harassments knowledge.

Based on the above discussion, high media exposure increases the level of knowledge, and an increase in the level of knowledge increases the level of prevention. In other words, high sexual harassments knowledge can prevent sexual harassments (Lonsway and Kothari, 2000).

Gurung, et al (2016), have done one study about knowledge of sexual harassments in the Udupi district among undergraduates' students. The author discussed that student's dignity, physical as well as mental health was affected by sexual harassments, and knowledge of sexual harassments can give courage students to be careful and aware of this problem. This research explores that $82.4 \%$ of the students had average knowledge, which indicated that students need more education-related sexual harassments to be aware and to prevent the crime. The authors conclude that more research needs to be done to assess the student's level of knowledge and awareness regarding sexual harassments. One part of the current study is done to measure the level of sexual harassments knowledge among students, of two Asian countries, based on this literature gap.

In Pakistani literature, seven studies (Mahmood and Ahmad, 2013; Muazzam and Qayyum, 2014; Durrani and Khan, 2015; Nauman and Abbasi, 2014; Anwar, et al., 2019; Yousaf and Schmiede, 2016) had done to investigate the sexual harassments knowledge but the six of them have workplace knowledge. Only four from six studies had shown that working women had the knowledge and can define and identify sexual harassments behavior but they are not willing to do written reports on being a victim. In addition, the other two studies (Muazzam and Qayyum, 2014; Durrani and Khan, 2015) showed that their respondents had no knowledge and they could not identify the sexual harassments and take this criminal act as a normal part of a routine.

However, one sexual harassments knowledge study (Haider and Mashud, 2014) had students as respondents. The author had discussed that although Pakistani students know a bit about the sexual harassments they were not comfortable answering knowledge questions.

Based on the above studies, there is a need to measure sexual harassments knowledge among students. There is a literature gap in measuring sexual harassments news exposure and its relation with knowledge and its relation with intolerant attitude and correct behavioral intentions.

In Malaysian literature, three studies (Jayapalan, et al., 2018; Nong et al., 2013; Endut et al., 2011) had done to measure sexual harassments knowledge among students. All these studies claimed that the majority of (above 50\%) Malaysian students have sexual harassments knowledge and willing to do written report on being a victim.

Yee, et al (2015) had focused on the differences in the perception of sexual harassments by gender and ethnicity among students. The authors had highlighted that both genders of three races (Malay, Chinese, and Indian) had sexual harassments knowledge but different ethnic groups perceive sexual harassments differently. The reason might be the religion and cultural differences. Another study of sexual harassments knowledge supports that Malaysian have sexual harassments knowledge but respondents were civil servants (Ali, et al., 2017). 
INTERNATIONAL JOURNAL OF ACADEMIC RESEARCH IN BUSINESS AND SOCIAL SCIENCES

Vol. 11, No. 15, Empowering Youth and Community Wellbeing for Sustainable Development, 2021, E-ISSN: 2222-6990 @ 2020 HRMARS

In a comparison of two Asian countries, Pakistan and Malaysia, there were studies to measured sexual harassments knowledge among Pakistani and Malaysian people. However, the relation of sexual harassments knowledge with sexual harassments news exposure, intolerant attitude towards sexual harassments, and propensity to act against sexual harassments is not mentioned.

In the current study, cultivation theory is applied to examine the relation of variables. As in the cultivation model, media exposure affects the attitude and behavior of the public (Sabri, 2017). In the present study, sexual harassments knowledge is an additional variable in the cultivation model to explore the relation of knowledge with news exposure, attitude, and behavior.

Furthermore, sexual harassments knowledge can help to form an intolerant mindset and behaviors to punish the perpetrators. Apaak and Sarpong, (2015) recommend that focus on sexual harassments knowledge can shift to empowerment and fearless environment gives the courage to fight with perpetrator against sexual harassments.

\section{Studies on the Relation of Intolerant Attitude towards Sexual Harassments with Sexual Harassments Knowledge}

EOC (2013) had discussed that the better understanding of sexual harassments can form attitudes and views towards sexual harassments but the findings of the report showed that students know little about that what sexual harassments constitutes but they cannot deal this situation in real life because of their non-serious attitude. This report concluded that the adult and university students (both male and female) in Hong Kong faced more sexual harassments than others did that affected their life. More awareness and education about both male and female sexual harassments prevention can develop a preventive attitude towards sexual harassments incidents in real life.

In America, the sexual harassments awareness movement called the \#MeToo movement brought different changes in attitude towards sexual harassments. Although it is not 100 percent change women become more concerned about sexual harassments allegations and men are more confused and careful in interaction with a female worker (Graf, 2018). In another U.S. study explored that Americans felt the change in their attitude towards sexual harassments. They felt more supported and empowered after this sexual harassments awareness campaign (Keplinger, et al., 2019).

However, there is one study that has been done in Australia after the \#MeToo movement to understand the attitude towards sexual harassments. The findings of this study showed that Australian people have a negative attitude towards sexual harassments even after having sexual harassments knowledge. In this study, researchers found that people have less empathy with sexual harassments victims and high empathy with perpetrators. It indicated that people have a victimblaming attitude which counts negatively (Bongiorno, et al., 2019). Poor knowledge of sexual harassments and have tolerating attitudes towards sexual harassments may be the reason for blaming the victim. Sexual harassments can be intolerant by better knowledge and less accepting attitudes towards sexual violence (Abeid, et al., 2015).

In Pakistan Haider and Mashud (2014) had discussed that Pakistani students have knowledge about sexual violence including sexual harassments but they have a tolerant attitude towards it. They remain silent and not comfortable to talk about it. Mostly Pakistani people had a negative and 
tolerant attitude towards sexual harassments (Durrani and Khan, 2015; Nauman and Abbasi, 2014; Mahmood and Ahmad, 2013; Anwar, Österman, and Björkqvist, 2019). However, all these studies are had discussed and mentioned the negative attitude but did not find out the relationship between sexual harassments knowledge and intolerant attitude towards sexual harassments. There is no specific study has been done in this area of research.

In Malaysian literature, there is no specific and comprehensive study to measure the relation between sexual harassments knowledge and intolerant attitude by using statistical methods. Although, the studies (Jayapalan, et al., 2018; Nong et al., 2013; Endut et al., 2011) had only discussed the people have sexual harassments knowledge and showing a positive attitude. However, it is not statistically approved and did not find any relationship between sexual harassments knowledge and intolerant attitude towards sexual harassments.

\section{Studies on the Relation among Propensity to Act against Sexual Harassments (Behavior), Sexual Harassments News Exposure, Sexual Harassments Knowledge and Intolerant Attitude towards Sexual Harassments}

Banyard, et al., (2007) had discussed that the society or community roles about their values who are in support of sexual harassments, particularly in colleges and universities. Every individual has to stand up against social standards that help sexual harassments and having aptitudes to be a successful and strong partner to survivors. This approach is considered as a bystander approach and in the present study; this behavioral intention is to define as the propensity to act against sexual harassments.

Many studies (e.g., Banyard, et al., 2004; Berkowitz, 2002; DeKeseredy, et al., 2000; Foubert, 2000; Foubert and Marriott, 1997; Katz, 1994; Slaby and Stringham, 1994; cited as in Banyard, et al., 2007), has been done to measure bystander behavior, which defined as Bystander approach or behavior, which identify the specific role of bystanders (on lookers) to follow. The utilization of the bystander approach to deal with the across the board issue of sexual harassments avoidance crosswise the campuses or other community networks.

Furthurmore, Bitton, and Shaul (2013) had explored that a less tolerant attitude towards sexual harassments predicted a stronger perception of behavior as manifesting sexual harassments. Women perceived sexual harassments behavior more than a man did and are less tolerant of sexual harassments. Sexual knowledge formed sexual attitudes and behaviors (Li, et al., 2013). Higher sexual knowledge decreases the level of tolerant attitude and behavior, showing the relation between knowledge, attitude, and behavior. Peng, et al (2009) explored that knowledge, attitude, and behavior had a significant positive relationship. However, the researchers did not focus on the relationship of all variables with media exposure.

Svensson, et al (2018) had indicated the relationship of knowledge about sexual harassments and attitude towards sexual harassments. The authors had explored that good knowledge of sexual harassments can develop an intolerant attitude towards sexual harassments. The researchers suggested that media is a source of information that can use for sexual harassments awareness but media exposure is not measured. 
In Pakistan, one study was done by Haider and Mahsud (2014) about knowledge, attitude, and practices of sexual violence included a small part of research on sexual harassments. The authors talked about knowledge, attitude, and practices of sexual violence but it is needed to find out the relationship among sexual harassments news exposure, knowledge, attitude, and behavior of Pakistani people.

Malaysian literature indicated the public has sexual harassments knowledge and willing to report but exposure to sexual harassments news is not explained in the literature (Jayapalan, et al., 2018; Nong et al., 2013; Endut et al., 2011).

Sexual harassments preventive news becomes indispensable since sexual harassments becomes a problem, it is crucial to spread awareness on prevention, law information, and causes. The media discussions on sexual harassments can develop intolerance and preventive or correct behavioral intentions against sexual harassments.

Principally recognized an important feature of sexual harassments prevention, is awareness. Sexual harassments knowledge can aware public to avoid the causes and become intolerant with the correct behavior. News media is considered an essential and effective means of uplifting knowledge in the development of intolerant attitude and behavior.

Hence, on the basis for hypothesizing direct relationships between sexual harassments news exposure and knowledge, attitude, and behavior in the present study. The level of sexual harassments news exposure forms a structural component of consideration in the policy of sexual harassments preventive awareness. Furthermore, for the reduction of tolerant and negative attitude and wrong behavior, the level of sexual harassments news exposure, knowledge, intolerant attitude and propensity to act against sexual harassment, should be measure.

\section{Objectives of the Study}

According to cultivation theory, exposure has relationship with attitude and behavior. In this study addition variable, SH knowledge is added to understand and identify the relationships with knowledge. The general objective is to determine the status of sexual harassment news exposure, knowledge, intolerant attitudes towards sexual harassment and behavioral reaction to sexual harassment, and the interrelationship among the variables surveyed.

- $\quad$ Identify the levels of SH news exposure, SH knowledge, intolerant attitude towards $\mathrm{SH}$, and propensity to act against $\mathrm{SH}$

- $\quad$ Determine the relationships among SH news exposure, and SH knowledge, intolerant attitude towards $\mathrm{SH}$, and propensity to act against $\mathrm{SH}$.

Theorizing Sexual Harassments News Exposure, Knowledge, Intolerant Attitude and Propensity to Act against Sexual Harassments and Media Agenda Setting on Sexual Harassments News Coverage Cultivation theory underpinned the core of this study that is the survey, offered a perspective of the relationships between sexual harassments news exposure and other variables of knowledge, intolerant attitude, and propensity to act against sexual harassments. Determining, how much the 
public reads sexual harassments news to get information, and may this information have a relation with their views and actions.

\section{Cultivation Theory}

The theoretical framework of the current research is on the premises of the cultivation theory. George Gerbner conceptualized the cultivation theory in the 1960s and 1970s. Cultivation theory is used to understand the media's effects on public views and practices (Sabri, 2017). This theory highlights the long-term effects of media on viewers (Mosharafa, 2015) and can change the real shape of the world that people think the world is more dangerous in real life (Melhem and PunyanuntCarter, 2019). The theory proposes that media can formulate a complete system of beliefs, values, perceptions, and concepts about violence or crime issues (Mosharafa, 2015). Singh and Gupta, (2006) states that the most basic form of cultivation theory is to reform or cultivate the reader's or viewer's concepts about the world.

There is a study done by Melhem and Punyanunt-Carter (2019) about Arab portrayals on television affects viewers' beliefs about Arabs in general. This study supports the cultivation theory that media exposure affects college students. The findings of this study suggest that television can affect the way college students view reality regarding Arabs with stereotypical behavior. The students thought that Arabs are the most dangerous in the world.

Not only television is a cultivating effect on students, but the news coverage of social and crime issues also cultivates the view of people. Lett, et al (2014) also support and discussed the cultivation effect of news media on people of the United States. This investigation explored relationships between viewing television news coverage of the September 11, 2001 attacks and perceptions of violence initiated by people outside the United States, negative personal emotions, and personal relationships. Results suggest that amount of television news viewing in the wake of the attacks is related to negative personal emotions, positive views of Islamic individuals in general, and negativity of personal relationships with Islamic peers. This study explored that news media can form people's minds, values, and cultivates their actions according to the media's specific agenda. As the author discussed that cultivation effects may be content biased (Lett, et al., 2014), it indicates that the content of news and news programs has cultivating power.

As mentioned above, the content has the power to change any thought and action. In other words, it can be discussed that the content of any social topic or criminal issue can educate and bring a change in society. It is not only about violence or crime coverage and its effects, but it is also about social development and awareness among the public. That is the reason the media coverage of the sexual harassments \#MeToo movement influences society. The coverage and persuasive content about sexual harassments details are bringing change in society and people are becoming less tolerant about sexual harassments. Together, the \#MeToo hashtag movement and its national news coverage have had an impact on the legal services that are available to victims of sexual harassments (Green, 2019). The findings of this study did not support the cultivation theory that is the reason the researcher recommended doing more researches on sexual content coverage.

Newspaper coverage is also a part of news media and has a cultivation effect on the public. Cultivation theory is one of the media effects theories and used for measuring mass communication 
effects. It has applied in media researches to determine the perceptions of life, shaped by continuous media exposure (Sabri, 2017).

Arentdt (2010) had supported the cultivation theory and explored the cultivation effect of a newspaper on its readers' reality estimates and attitudes. Additionally, the study tries to advance cultivation research by examining implicit attitudes. The author had done a content analysis of four months of news coverage in one particular newspaper showed that foreigners were overrepresented as offenders and that the newspaper had a negative view of the EU. According to cultivation theory, it is assumed that the more people read a newspaper, the more their reality estimates and attitudes correspond to the recurrent, stable, and overarching patterns of the newspaper's content. The data show evidence of a significant causal influence of newspaper exposure on implicit attitudes and a marginally significant causal effect on the overestimation of foreigners as offenders and explicit attitudes.

However, another study of Saudi newspaper exposure has been done by Sabri (2017). The author used cultivation theory to examine the effects of Saudi Arabian print media (newspapers) on nationals and expatriates living in Jeddah, Saudi Arabia. In contrast, to the above studies, the results revealed that there was no relationship between the level of readership and personal perceptions of crime levels; there is no statistical significance between the level of newspaper exposure and the formation of their views and concepts about the crime. The author suggested news development or addition to the cultivation theory model.

Cultivation theory assumes that Media is very influential and it can mold the public's attitude and behavior. It can cultivate the social norms in any culture. Although, media does not present reality but creates scenarios. Viewing more can lead to behavioral change. The current study has hypothesized a few assumptions based on cultivation theory. They are the following:

- Frequently readers of sexual harassments news stories have high exposure

- High sexual harassments news exposure enhances the sexual harassments knowledge

- High sexual harassments news exposure can form or mold social conservative and tolerant views into intolerance

- Reading more sexual harassments news, more knowledge, which can lead the intolerant attitude and correct behavioral change

\section{Conceptual Model and Hypothesis Development}

This study seeks to clarify the roles of key variables in the cultivation theory (Morgan et al., 1990) with knowledge as an additional variable. The key assumption in this version of the cultivation model is that sexual harassments news exposure can enhance sexual harassments knowledge in respondents that helps to develop an intolerant attitude and propensity to act against sexual harassments. This study set out to investigate the sexual harassments news exposure of Pakistani and Malaysian people and determine its relationship with other variables.

Furthermore, one study by Sabri (2017) had done in Jeddah, Saudia Arabia. The findings showed no significant effect of the newspaper on the public's view and actions, but at the same time, the study mentioned the gap. The author suggested adding additional variables that may change the relation 
INTERNATIONAL JOURNAL OF ACADEMIC RESEARCH IN BUSINESS AND SOCIAL SCIENCES

Vol. 11, No. 15, Empowering Youth and Community Wellbeing for Sustainable Development, 2021, E-ISSN: 2222-6990 @ 2020 HRMARS

of exposure to attitude and behavior. The researcher recommended checking coverage in the Urdu language newspaper or other languages also. Green (2019) also highlighted the same results as Sabri (2017) mentioned. The author also recommended adding a variable in the cultivation model for better results.

This prediction is inspired by figured relationships between sexual harassments news exposure and knowledge (Aransay, et al., 2015), between sexual harassments news exposure and intolerant attitude (Arentdt, 2010), sexual harassments knowledge, attitude and behavior (Li, et al., 2013).

\section{Hypothesis}

H1: Sexual harassments news exposure has a positive relationship with the propensity of an act against sexual harassment.

H2: Sexual harassments news exposure has a positive relationship with the intolerant attitude towards sexual harassment.

H3: Sexual harassments news exposure has a positive relationship with sexual harassments knowledge

H4: Sexual harassments knowledge has a positive relationship with an intolerant attitude towards sexual harassment.

H5: Sexual harassments knowledge has a positive relationship with the propensity to act against sexual harassment.

H6: Intolerant attitude towards sexual harassment has a positive relationship with the propensity to act against sexual harassment.

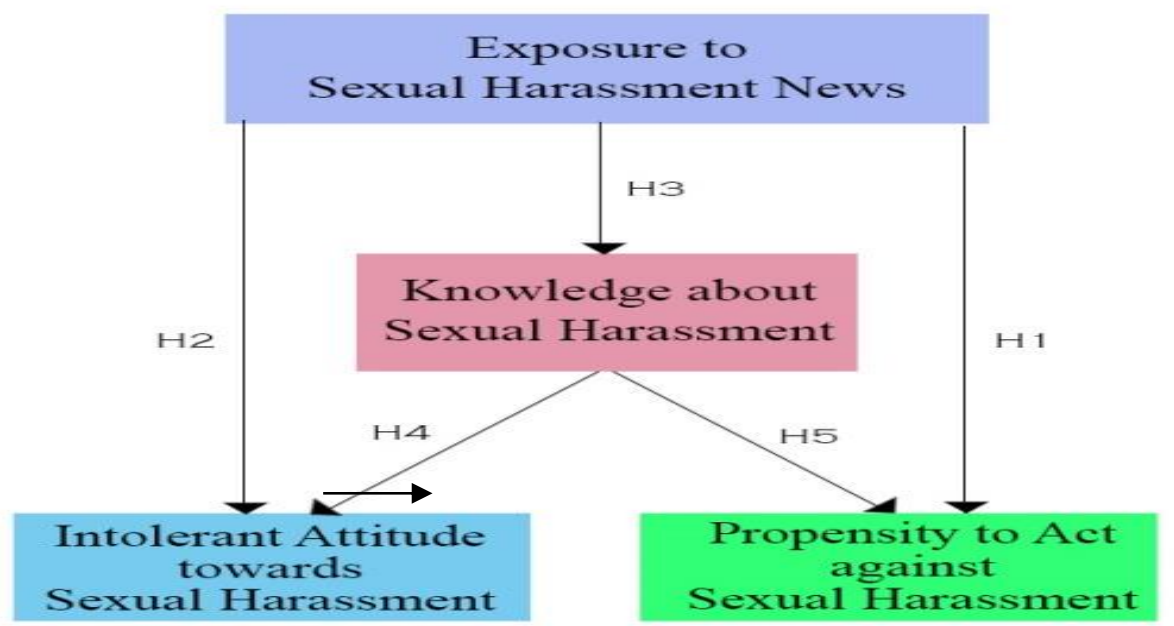

Figure 1: Conceptual Model of sexual harassments News Exposure, Knowledge, Intolerant Attitude, and Propensity to act against sexual harassments 


\section{Methodology}

The face-to-face survey methodology will be administered. The survey questionnaire will be consisted of five sections. Section A will be consisting of 17 items to measure demographic variables. In this section, experience and awareness questions will be also included to investigate the respondent's awareness about sexual harassment. Section B will be measure sexual harassment news exposure. Refer to the frequency of exposure to five different categories of SH news definition, preventive measure, sensational news, consequences, and legal aspects of sexual harassment monthly. On a 5point scale from never (1) to very often (5), respondents will be asked to indicate how frequently they read on the 5 categories of SH news in the media. Responses to the items will aggregated to index degree of exposure to $\mathrm{SH}$ news, a higher score will indicate higher exposure. Section $\mathrm{C}$ will measure the respondent's knowledge about sexual harassment. This section will cover different types of sexual harassment (visual, verbal, physical psychological), a measure of variables is specifically developed to the purpose of the study of the knowledge. Knowledge about sexual harassment will refer to the understanding of what behavior constitutes sexual harassment. Respondent will be given 11 scenario items (representing the 5 different forms of $\mathrm{SH}$ ) and asked to indicate whether the scenarios constitute an act of $\mathrm{SH}$ or not. Respondent will also ask 2 items relating to general knowledge about SH. Responses to the 13 items are aggregated to create a composite score as an index of SH knowledge. A higher score means a higher level of knowledge. Section D will measure attitudes toward $\mathrm{SH}$, refer to the degree of intolerance to act of SH. Respondent will be asked 10 five-point Likert items to indicate the extent to which he/she agree or disagree with the statements, from strongly disagree (1) to strongly agree (5), A composite mean score will be computed to an index level of attitudes toward SH. A higher mean score means higher intolerance toward SH. This instrument will be adapted from the previous study, teachers' attitude toward sexual harassment and perceptions of student peer sexual harassment' (Marilyn Suzann McLeroy Stone, 2001). Section E will measure Propensity to act against SH. Refer to the degree of behavioral intention to express disapproval and take appropriate action to fight $\mathrm{SH}$. Respondent will be asked 12 five-point Likert items to indicate the degree to which he/she agree or disagree with the items, from strongly disagree (1) to strongly agree (5). This instrument will be adapted from a study 'the UO sexual violence and institutional behavior campus survey' (Freyd, 2014). An arbiter analysis (Carmines \& Zeller, 1979) will be done for the content validation of the instrument. In this procedure, the researcher contacted many experts in mass communication, psychology, and sociology fields (Creswell, 2012). The unit of analysis in the survey was the adult students aged 18 or over 18years. This study will be carried out in two countries, Pakistan and Malaysia. Both countries have a relatively large population. Specifically, the surveys will be conducted in the city of Lahore major city (Haider \& Mashud, 2014) in Pakistan and Kuala Lumpur, Malaysia. Both cities have universities, which were deemed eligible for the sampling method to be used. According to Raosoft, the minimum sample size of this study is 389 given the confidence level of $95 \%$ and a confidence interval of 5 . The proposed sampling frame of this research is based on the convenience sampling method. The sampling frame is mentioned below in Figure 2. 


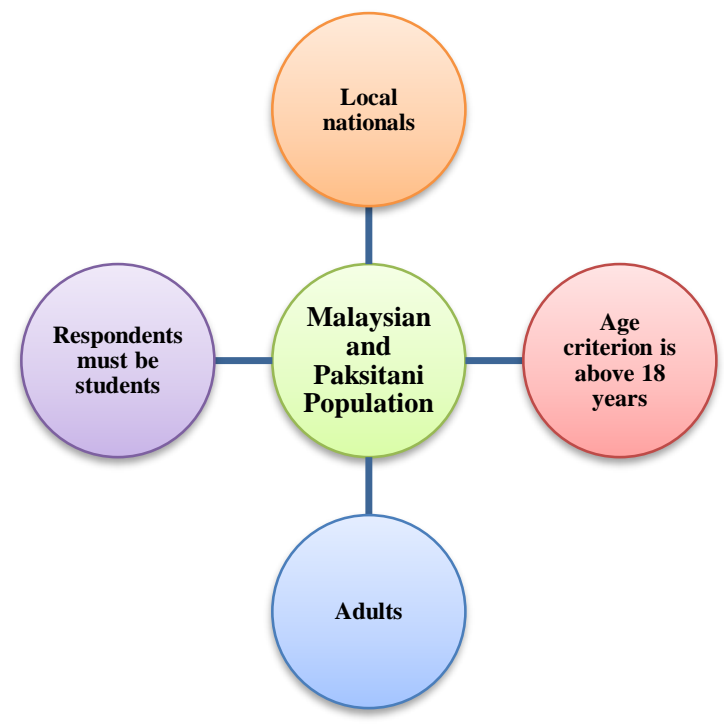

Figure 2: Sampling Frame

Baker's (1999) guidelines, 38.5 approximately 39 questionnaires (approximately 10\% of total sample size) will be administered on the pilot study respondents. The pilot study will be carried out to check the instructions and to see if there will be any ambiguities or if the respondents have any difficulty in responding (Vaus, 1993). After pilot study, the survey will be done. Data analysis will be done by using Multiple Linear Regression on SPSS (version 22).

\section{Conclusion}

According to evidence, sexual harassments knowledge can be tested to measure the relationship with sexual harassments news exposure, intolerant attitude, and propensity to act against sexual harassments. It is concluded that sexual harassments news content should be very effective, informative and positive then the high sexual harassments news exposure can generate high knowledge and shows good relationship. Based on the above literature, sexual harassments knowledge develops intolerant attitude and propensity to act against sexual harassments.

Sexual harassment news exposure, with informative content, can enhance the sexual harassments knowledge that can generates intolerant attitude and correct behavior. The news media needs to practice positive and awareness content for the sexual harassment coverage. Based on Paracha and Tahir (2012) study, the higher authorities and media organizations should endorse such strategies and plans that can help to implement this conceptual cultivation model for the purpose of recovery from sexual harassment, a silent crime.

The future researchers can use sexual harassments knowledge variable as a mediator or moderator to measure the cause and effect of sexual harassments knowledge with sexual harassments news exposure, intolerant attitude, and propensity to act against sexual harassment.

\section{References}

Abeid, M., Muganyizi, P., Massawe, S., Mpembeni, R., Darj, E., \& Axemo, P. (2015). Knowledge and attitude towards rape and child sexual abuse - a community-based cross-sectional study in Rural Tanzania. BMC Public Health 15:428. 
Ahmed, S. (2014). Voilence against women: Media representations of voilent issues in the perspective of Pakistan. Science International, 367-371.

Alagappar, P. N., \& Marican, S. (2013). Media coverage of sexual harassments in Malaysia: A content analysis case study. IPEDR, 17-21.

Alagappar, P. N., \& Marican, S. (2014). The issue of sexual harassments harassment legislation in a mainstream newspaper in Malaysia. Procedia- Socal and Behavioral Sciences, 368-373.

Alagappar, P. N., and Lean, M. L., David, M. K., and Ishak, Z., and Ngeow, Y. M. (2011) "You're so hot!": A content analysis of sexual harassment among hotel employees. In: 2011 International Conference on Humanities, Society and Culture, 04-06 Nov 2011, Kuala Lumpur 17- 21

Ali, A., Jangga, R., Bakar, S. Z., Basir, N., \& Mohamad, S. (2017). Level of awareness among Johor Civil servants towards sexual harassments in the workplace. International Journal for Studies on Children, Women, Elderly and Disabled, 2(June); 44-51

Alivi, M. A., Ghazali, A. H. A., Tamam, E., \& Osman, M. N. (2018). A review of new media in Malaysia: Issues affecting society. International Journal of Academic Research in Business and Social Sciences, 8(2), 12-29

Anwar, F., Österman, K., \& Björkqvist, K. (2019). Three types of sexual harassments of females in public places in Pakistan. Journal of Contemporary Medicine, 9(1):65-73

Apaak, D., \& Sarpong, E. O. (2015). Knowledge level and incidence of sexual harassments in sports: Views of Ghania Female University Athletes. Journal of Educational and Social Research, 121130.

Aransay, E. A., Pasoot, M. A., \& Tong, S. A. (2015). The relationship of exposure to mass media and knowledge on and attitude towards disaster preparedness among resident of Barngay Makiling, Calamba City. Journal of Arts and Sciences Communication Research, 2(1): 286-307

Arendt, F. (2010). Cultivation effects of a newspaper on reality estimates and explicit and implicit attitudes. Journal of Media Psychology: Theories, Methods, and Applications, 22(4), 147-159.

Asif, M. (2010). Violence against women in Pakistan: Role of police and media. Social Sciences Review of Pakistan, 13-21.

Asp, G., Pettersson, K. O., Sandberg, J., Kabakyenga, J., \& Agardh, A. (2014). Associations between mass media exposure and birth preparedness among women in southwestern Uganda: $A$ community-based survey. Global Health Action.

Banyard, V. L., Moynihan, M. M., \& Plante, E. G. (2007). Sexual voilence prevention through bystander education: An experimental evaluation. Journal of Community Psychology, 35(4): 463-481.

Banyard, V., Moyniham, M. M., \& Warner, R. (2014). How do we know if it works? Measuring outcomes in Bystander focused abuse prevention on campus. Psychology of Voilence, 4(1): 101115.

Baker, T. L. (1999). Doing Social Research. Boston: McGraw-Hill College.

Bitton, M. S., \& Shaul, D. B. (2013). Perceptions and attitudes to sexual harassments: An examination of sex differences and the sex composition of the harasser-target dyad. Journal of Applied Social Psychology, 43(10): 2136- 2145

Bongiorno, R., Langbroek, C., Bain, P. G., Ting, M., \& Ryan, M. K. (2019). Why women are blamed for being sexually harassed: The effects of empathy for female victims and male perpetrators. Psychology of Women Quarterly, 44(1): 11-27

Carmines, E. G., \& Zeller, R. A. (1979). Reliability and Validity Assessment. Sage Publishers

Charlesworth, S., \& McDonald, P. (2012). Framing sexual harassments through media representations. Women's Studies International Forum, 37: 95-103 
INTERNATIONAL JOURNAL OF ACADEMIC RESEARCH IN BUSINESS AND SOCIAL SCIENCES

Vol. 11, No. 15, Empowering Youth and Community Wellbeing for Sustainable Development, 2021, E-ISSN: 2222-6990 @ 2020 HRMARS

Creswell, J. W. (2012). Educational Research, Planning, Conducting, And Evalualting Quantitative and Qualitative Research. University of Nebraska, Linkon: Pearson.

De Vaus, D. A. (1993), Surveys in Social Research (3rd edn.), London: UCL Press.

Durrani, A., \& Khan, R. M. (2010). Intruding intimacies: Sexual harassment of women academics in Pakistani universities. International Journal of Sustainable Development, 1, 46-56

Endut, N., Oon, S. W., Teng, L. W., Azmi, Z., Ali, S. H., \& Hashim, R. (2011). Understanding and experiences of sexual harassments amongst university students: A case study of undergraduates in Universiti Sains Malaysia. International Proceedings of Economics Development and Research 20, 7-11

Equal Opportunities Commission (EOC) and the Department of Special Education and Counselling of Hong Kong Institute of Education. (2013). Study on students' sexual attitudes and views on sexual harassment. Retrieved from http://www.eoc. org.hk/EOC/Upload/Rese archReport/SH_eFullReport.pdf.

Gewijzigd, L. (2003). Agenda-Setting Theory. Retrieved from TCW: http://www.tcw.utwente.nl/theorieenoverzicht/Theory\%20clusters/Mass\%20Media/AgendaSetting_Theory.doc/

Graf, N. (2018). SH at Work in the era of \#MeToo. Retrieved from Pew Research Center : https://www.pewsocialtrends.org/2018/04/04/sexual-harassment-at-work-in-the-era-ofmetoo/

Green, J. R. (2019). The \#MeToo movement and cultivation theory: A quantitative research communication study. Wichita State University.

Gurung, A., Priyadarshini, S., \& E., B. M. (2016). Knowledge of sexual harassments among the undergraduate students in Udupi District. Nitte University Journal of Health Science, 6(2): 4-9.

Gutek, B. (1995). How subjective is sexual harassments? An examination of rater effects. Basic and Applied Social Psychology, 447-467.

Gutek, B. A. (1995). The dynamics of service: Reflections on the changing nature of customer/provider interactions. Jossey-Bass.

Haider, S. I., \& Mashud, M. N. (2014). Knowledge, attitude, and practices of voilence (a study of university students in Pakistan). Journal of Sociology and Social Work, 2(1): 123-145

Happer, C., \& Philo, G. (2013). The role of media in the construction of public belief and social change. Journal of Social and Political Psychology, 321-336.

Jayapalan, A., Wong, L. P., \& Aghamohammadi, N. (2018). A qualitative study to explore understanding and perception of sexual abuse among undergraduate students of different ethnicities. Women's Studies International Forum, 69, 26-32

Jennifer, J., Freyd, M. R. (2014). Survey Questions the UO Sexual Voilence and Institutional Behavior Campus Survey.

Keplinger, K., Johnson, S. K., Kirk, J. F., \& Barnes, L. Y. (2019). Women at work: Changes in sexual harassments between September 2016 and September 2018. PLoS One, 14(7):1-20

Lett, M. D., DiPietro, A. L., \& Johnson, D. I. (2014). Examining effects of television news violence on college students through Cultivation Theory. Communication Research Reports, 21(1): 39-46

Li, S., Chen, R., Cao, Y., Li, J., Zuo, D., \& Yan, H. (2013). Sexual knowledge, attitudes and practices of female undergraduste studnets in Wuhan, China: The only child versus students with siblings. PLOS ONE, 8(9): 1-8

Lonsway, K. A., \& Kothari, C. (2000). First year campus acquaintance rape education: Evaluating the impact of a mandatory intervention. Psychology of Women Quarterly, 24(3): 220-232 
Mahmood, Q. K., \& Ahmad, I. (2011). Perception of sexual harassments at workplace, knowledge and attitude of working women towards workplace Harassment Act 2010. Social Sciences Review of Pakistan, 1(1): 22-29

Marilyn Suzann McLeory Stone. (2001). Teachers' Attitude Toward Sexual Harassment And Perceptions Of Student Peer Sexual Harassment.

Melhem, S., \& Punyanunt-Carter, N. M. (2019). Using Cultivation Theory to understand American college students' perceptions of Arabs in the media. Journal of Muslim Minority Affairs, 39(2): 259-271

Morgan, Michael, Shanahan, J., \& Harris, C. (1990). "VCRs and the effects of television: New diversity or more of the same?". In I. J. (ed.), Socialanct Cultural Aspects of VCR Use (pp. 107-123). NJ Hillsdale: Erlbaum.

Mosharafa, E. (2015). All you need to know about: The Cultivation Theory. Global Journal of HumanSocial Science, 15(8): 23- 37

Muazzam, A., \& Qayyum, F. (2016). Experiences of sexual harassments: Interplay of working environment, depression and self-esteem in Pakistani Women. Pakistan Journal of Social and Clinical Psychology, 42-46.

Nauman, B., \& Abbasi, A. (2014). Sexual Haarssment at workplace: A case of banking sector in Lahore. Middle-East Journal of Scientific Research, 20: 558-566

Nautiyal, V., \& Dabral, M. (2012). Women issues in newspapers of Uttarakhand. Global Media Journal -India Edition, 3(1): 1-10

Nong, S. N., Bidin, A., Mohamad, A., Harun, N., \& Pauzai, N. A. (2013). Sexual harassments amongst undergraguadete students at a public university in the East Coast of Peninsular Malaysia, Malaysia. International Journal of Education and Research, 1(7): 1-10

Paracha, S. A., \& Tahir, S. N. (2012). Role of all Pakistani Newspapers Society (APNS): Call for a change. Role of All Pakistani Newspapers Society, 6(1): 17-26

Peng, Y., Shen, L., Wo, J., Xiang, Y., \& Erxia, L. (2009). Characteristics and relationship between sexual behavior, sexual attitude and sexual knowledge in college students. Population Research, 33(6): 85-93

Philo, G. (2008). Active audiences and the construction of public knowledge. Journalism Studies, 9: 535-544

Sabri, A. (2017). Cultivation effects of Saudi newspapers on estimates of expatriate crime. Retrieved from http://dar.aucegypt.edu/handle/10526/4982

Shoemaker, P. J., \& Reese, S. D. (1996). Mediating the message theories of influences on mass media content. USA: Logman Publishers.

Singh, M. R., \& Gupta, A. (2006). Cultivation and conservation practices of Euryale Ferox Salisab in Manipur. Indian Journal of Traditional Knowledge, 5(1): 143-144

Svensson, J., Baer, N., \& Silva, T. (2018). Adolescents' level of knowledge of and supportive attitudes your sexual crime in the Swedish context. Journal of Sexual Aggression, 25(1): 1-15

Thorton, J. A., \& Wahl, O. F. (1996). Impact of a newspaper article on attitudes toward mental illness. Journal of Community Psychology, 24(1): 17-25

Wakefield, M. A., Loken, B., \& Hornik, R. C. (2010). Use of mass media campaigns to change health behaviour. The Lancet, 1261-1271.

Winburn, J., Winburn, A., \& Niemeyer, R. (2014). Media coverage and issue visibility: State legislative responses to school bullying. The Social Science Journal, 514-522. 
Yee, M. W., Alagappar, P. N., \& Ngeow, Y. M. (2015). Differences in the perception of sexual harassments by gender and ethnicity among selected Malaysian undergraduates. Gender, Technology and Development, 204-230.

Yousaf, R., \& Schmiede, R. (2016). Harassment Act implementation in Higher Education Institutions. Open Journal of Leadership, 5: 8-19 